\title{
Effects of Mentha Piperita Essential Oil Uptake or Inhalation on Heart Rate Variability and Cardiopulmonary Regulation during Exercise
}

\author{
Tso-Yen Mao', Chun-Feng Huang ${ }^{1,2}$, De-Yen Liü,4, Chien-Ting Chen ${ }^{5}$, Chin-Cheng Yang ${ }^{1,6}$ \\ Affiliations: 'Chaoyang University of Technology, Department of Leisure Services Management, Taichung, Taiwan (R.O.C), ${ }^{2}$ National Yang Ming Chiao \\ Tung University Hospital, Department of Family Medicine, Yilan, Taiwan (R.O.C.), ${ }^{3}$ St. Mary's Junior College of Medicine, Nursing and Management, \\ Department of Health and Leisure Management, Yilan, Taiwan (R.O.C), ${ }^{4}$ National Taiwan Normal University, Graduate Institute of Sport, Leisure and \\ Hospitality Management, Taipei, Taiwan (R.O.C), ${ }^{5}$ Chung Yuan Christian University, Office of Physical Education, Taoyuan, Taiwan (R.O.C.), ${ }^{6}$ National \\ Yunlin University of Science and Technology, Graduate School of Technological and Vocational Education, Yunlin, Taiwan (R.O.C.)
}

Correspondence: C.-C. Yang, Chaoyang University of Technology, Department of Leisure Services Management, 168, Jifeng E. Rd., Wufeng District, 413, Taichung, Taiwan (R.O.C). E-mail: ccyang.author@gmail.com

\begin{abstract}
This study compares the effects of the uptake or inhalation of 50uL Mentha piperita (MP) essential oil for 10 days on heart rate variability (HRV) and cardiopulmonary regulation during various exercise intensities. Forty-eight healthy male subjects were randomly assigned to MP uptake (MPU; $n=16)$, MP inhalation (MPI; $n=16)$, and control group ( $; ; n=16)$. All participants were measured resting HRV, respiratory, cardiovascular, and metabolic parameters during aerobic, anaerobic, and graded exercise tests (GXT) before and after treatment. There were significant increases in the low-frequency area $\left(\mathrm{LFa} ; 1.8 \pm 0.1 \mathrm{vs} 2.2 \pm 0.2 \mathrm{~ms}^{2}\right.$ ), the ratio of low frequency to respiration frequency area (LFa/RFa; $\left.0.9 \pm 0.1 \mathrm{vs} 1.3 \pm 0.1\right)$ at resting and carbon dioxide production $\left(\mathrm{VCO}_{2} ; 41.2 \pm 4.0 \mathrm{vs} 49.2 \pm 6.8 \mathrm{~mL} / \mathrm{min}^{-1} / \mathrm{kg}^{-1}\right)$, ventilation per minute $\left(\mathrm{V}_{\mathrm{E}} ; 80.2 \pm 4.3 \mathrm{vs}\right.$ $\left.97.5 \pm 5.5 \mathrm{~L} / \mathrm{min}^{-1}\right)$, and respiratory rate (RR; $38.2 \pm 1.9$ to $44.3 \pm 2.1$ breath $\left./ \mathrm{min}^{-1}\right)$ in an anaerobic test following MPU intervention. In GXT, maximal carbon dioxide production $\left(\mathrm{VCO}_{2 \max } 51.9 \pm 3.5\right.$ to $\left.59.1 \pm 6.4 \mathrm{~mL} / \mathrm{min}^{-1} / \mathrm{kg}^{-1}\right)$, maximal ventilation per minute $\left(\mathrm{V}_{\text {Emax }} ; 126.4 \pm 6.5\right.$ to $\left.138.4 \pm 5.4 \mathrm{~L} / \mathrm{min}^{-1}\right)$ and maximal respiratory rate $\left(\mathrm{RR}_{\text {max }} ; 52.7 \pm 3.6\right.$ to $\left.60.1 \pm 2.3 \mathrm{breath} / \mathrm{min}^{-1}\right)$ significantly increased in MPU. The correlations of $\Delta \mathrm{LFa}$ with $\Delta \mathrm{VCO}_{2 \max } \Delta \mathrm{V}_{\mathrm{Emax}}$ and $\Delta \mathrm{RR}_{\max }$ in the MPU group were significant. Continuous uptake or inhalation of 50uL MP oil for 10 days does not improve aerobic capacity and maximal exercise performance, but 10 days' uptake of MP essential oil increased sympathetic activity at rest and may relate to respiratory regulation under high-intensity exercise.
\end{abstract}

Keywords: essential oil, ergogenic aids, aromatherapy, ventilation threshold, carbon dioxide

$@$ MJSSMontenegro

MENTHA PIPERITA ESSENTIAL OIL ON EXERCISE PERFORMANCE

http://mjssm.me/?sekcija=article\&artid=225

Cite this article: Mao, T., Huang, C., Liu, D., Chen, C., \& Yang, C. (2021). Effects of Mentha Piperita Essential Oil Uptake or Inhalation on Heart Rate Variability and Cardiopulmonary Regulation during Exercise. Montenegrin Journal of Sports Science and Medicine, 10 (2), 65-72. doi: 10.26773/mjssm.210910

\section{Introduction}

Many scientific researchers are still attempting to increase athletic performance with supplemented natural plant prod- ucts. Various essential oils extracted from aromatic plants have biological effects on human health (Elshafie \& Camele, 2017). Mentha piperita (MP) is a common species in the La-

Received: 8 February 2021 | Accepted after revision: 15 April 2021 | First published online: 1 September 2021

(c) 2021 by the author(s). License MSA, Podgorica, Montenegro. This article is an open access article distributed under the terms and conditions of the Creative Commons Attribution (CC BY).

Conflict of interest: None declared. 
miaceae family (Watanabe et al., 2015) and has been shown to have the effects of anti-spasticity, anti-pain, anti-inflammation, anti-oxidation, and analgesic effects (Gobel et al., 1994; McKay \& Blumberg, 2006; Scherer et al., 2013). MP essential oil has also been proven to be related to the treatment of headaches (Mauskop, 2001), irritable bowel disease (Alammar et al., 2019), and other diseases (McKay \& Blumberg, 2006). MP essential oil contains more than 40 kinds of chemicals, primarily menthol at about $29 \%$ and menthone at about $20-30 \%$ (Rohloff, 1999), and has confirmed the safety of eating mint (Ahijevych \& Garrett, 2004).

Whether through direct nasal inhalation or mixing with the aqueous solution for oral uptake, is MP essential oil has effective in enhancing athletic performance? Previous studies found inhalation of MP essential oil was effective in improving physical fitness (including running speed, handgrip strength, and the number of push-ups) (Raudenbush et al., 2001), increasing oxygen saturation $\left(\mathrm{SpO}_{2}\right)$, heart rate $(\mathrm{HR})$, blood pressure (BP), and mean arterial pressure (MAP) during a 15-minute treadmill stress test (Raudenbush et al., 2002), typing performance test (Barker et al., 2003) and aerobic performance and reaction time (Asghar, 2011).

Furthermore, Jaradat et al. (2016) demonstrated that inhaling MP essential oil through the nose improved expiratory volume in the first second $\left(\mathrm{FEV}_{1}\right)$, forced vital capacity (FVC), running speed (Jaradat et al., 2016). However, Pournemati et al. (2009) found that there was no effect on maximal heart rate $\left(\mathrm{HR}_{\max }\right)$, running time, maximal oxygen uptake $\left(\mathrm{VO}_{2 \max }\right)$, oxygen consumption $\left(\mathrm{VO}_{2}\right)$, ventilation per minute $\left(\mathrm{V}_{\mathrm{E}}\right)$, and respiratory exchange rate (RER) in female soccer athletes following MP inhalation (Pournemati et al., 2009). To date, the impact and mechanism of inhaling MP essential oil on athletic performance remain controversial.

There are many ways to orally uptake MP essential oil, including direct oral consumption, drink in aqueous solutions of essential oil, or infusion of mint leaves. Sönmez et al. (2010) confirmed that oral intake supplemented with a water solution soaked in mint leaves offered no improvement in running speed on a 400-metre test, but lactic acid in the blood and muscular pain level significantly decreased as compared to other treatments. Meamarbashi and Rajabi (2013) found that subjects who drank 50uL MP aqueous solution for 10 consecutive days enhanced FVC, peak expiratory flow (PEF), peak inspiratory flow (PIF), and time to exhaustion, maximal workload, and $\mathrm{VO}_{2 \max }$. Moreover, direct oral administration of 50uL MP oil increased grip strength, standing vertical jump, standing long jump, $\mathrm{FVC}_{1}$, PIF, PEF, and reaction times (Meamarbashi, 2014). Similarly, the benefits of uptake MP essential oil are still questioned. Shepherd and Peart (2017) indicated that uptake of MP essential oil for 10 consecutive days does not improve aerobic capacity.

Many essential oils affect the autonomic nervous system by stimulation (increased sympathetic activity) or soothing (increased parasympathetic activity). Previous studies have also confirmed essential oils with a stimulating effect, such as grapefruit (Horii et al., 2015), peppermint, estragon, and fennel (Haze et al., 2002), while other essential oils such as lavender, geranium, chamomile, sandalwood, bergamot, rosemary, and similar, have soothing effects (Chang \& Shen, 2011; McCaffrey et al., 2009; Seo, 2009). The fragrance is an essential oil that stimulated the olfactory system and thus affected brain waves (Lorig \& Schwartz 1988) or stimulated or inhibited brain functions (Manley 1993). Komori et al. (1995) pointed out that fragrance affects the endocrine function by changing the concentration of cortisol and dopamine in urine and the activity of the natural killer cell, which also affects the immune function. In an animal experiment, menthol vapour was proved to reduce surfactant and further change lung surface tension and lung function (Zänker et al., 1980). Previous studies have also shown that fragrance had effects on the autonomic nervous system by observed on HR, skin conductance, respiration (Brauchli et al. 1995), and blood pressure (Heubergber et al. 2001).

Based on the above studies, the results of enhanced athletic performance by continuous uptake or inhalation of MP essential oil are still conflicting. The present study designs a randomized controlled trial (RCT) to validate the effects of 50 uL MP essential oil uptake or inhalation on autonomic, respiratory, cardiovascular, and metabolic systems and to identify possible mechanisms by which MP essential oil affects athletic performance. The purposes of this study are as follows: first, confirm the effects of 50uL intake or inhalation of MP essential oil on athletic performance for 10 consecutive days, including in aerobic, anaerobic, and maximum exercise performance. Second, confirm whether $50 \mathrm{uL}$ intake or inhalation of MP essential oil for 10 days will affect the autonomic nervous system and thus change respiratory, cardiovascular, and metabolic regulation during exercise.

\section{Methods}

Healthy male participants aged 20 to 30 years old were recruited from two universities. The conditions of the participants were: not smoking, no cardiovascular diseases, no lung-related diseases, no neurological diseases or metabolic diseases, no daily use of any dietary supplement, and no use of mint-related products during the experiment. This research was approved by the Institutional Review Board of Catholic St. Mary's Hospital (No. IRB104001). All participants agreed and signed informed consent before the study. The 48 participants were randomly assigned to MP Uptake Group (MPU, n=16), MP Inhalation Group (MPI, $n=16$ ), and Control Group (C, $\mathrm{n}=16$ ) by a random table. Two subjects of the MPI group unable to complete the study due to personal reasons. The experimental achievement rate was thus $95.83 \%$.

Before the formal MP uptake or inhalation experiments were performed, the subjects underwent two sensitization tests. Each participant underwent an anthropological parameter measurement and a skin sensitization test that involved the application of $1 \%$ of MP on the inner skin of the upper arm in order to monitor whether the participant exhibited any allergic responses (redness, swelling, heat, or pain). If an allergic response was observed within 24 hours, the subject was subsequently excluded. After that, the participants performed an MP spray inhalation sensitization test. Each inhaled $1 \%$ of MP $(50 \mu \mathrm{L})$ for $10 \mathrm{~min}$ and was then monitored for 24 hours. As in the previous test, if an allergic response was observed or if any participant experienced discomfort, they were excluded. All participants had passed the sensitization tests before participating in the follow-up intervention experiment.

This study designed a single-blind RCT due to the strong taste of MP essential oil that may result in different results between inhalation and uptake intervention. The single-blind design was expected to minimize the recognition of the researchers by the groups of subjects. After signing the informed 
consent, the heart rate variability (HRV) test was measured on Day 1. All subjects were given a treadmill graded exercise test (GXT) on Day 2 to measure the maximal exercise performance. On Day 4 (an interval of 48 hours), subjects were given a six-minute $80 \%$ ventilatory threshold (VT) exercise test for aerobic endurance. On Day 6 (an interval of 48 hours), subjects were given a six-minute $\Delta 50(50 \%$ of VT and maximal workload) exercise test for anaerobic endurance.

The MPU group drank peppermint oil-water $(500 \mathrm{~mL}$ aqueous solution containing 50uL of MP essential oil) for 10 consecutive days under the laboratory researchers' monitoring; the daily intake was recorded, and the study monitored whether there were any adverse reactions. For the MPI group, $50 \mathrm{uL}$ of peppermint oil spray was inhaled for 10 consecutive days in the laboratory. The spray was manufactured using an ultrasonic spray-manufacturing machine (KUN-808, K. SONIC, Taiwan), and the nose of the subject was connected with a catheter and a mask. The laboratory researchers confirmed that the subject completely inhaled $50 \mathrm{uL}$ MP essential oil spray to ensure the dosage of MP essential oil was consistent between MPU and MPI groups. Subjects' daily intake and any adverse reactions were recorded by laboratory researchers. The Control Group was asked to maintain a daily lifestyle and prohibited using MP essential oil products during the experiment. MP essential oil was selected from the products manufactured by the U.S. dealer FBI, and the products had qualified production and safety certificates (Name: Mentha piperita; No: 31060). The amount of MP essential oil in this study was determined according to previous studies and confirmed the dosage was lower than the daily uptake recommended by the U.S. FDA (Meamarbashi, 2014; Meamarbashi \& Rajabi, 2013; Nair, 2001). The experimental design of this study is shown in Figure 1.

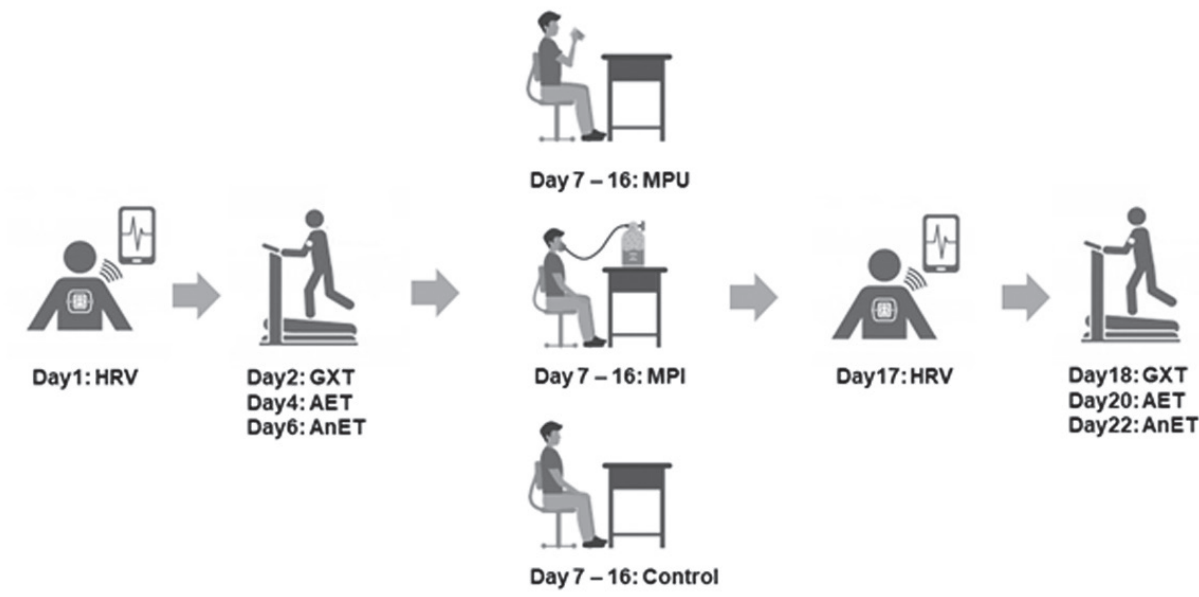

Figure 1. Experimental design of this study. HRV: heart rate variability; GXT: Graded exercise test; AET: Aerobic endurance test; AnET: Anaerobic endurance test; MPU: Mentha piperita essential oil uptake group; MPI: Mentha piperita essential oil inhalation group; Control: control group.

The GXT was performed by modified Bruce protocol. In short, the subjects were rested in a sitting position for two minutes before the test. When the $\mathrm{VO}_{2}$ and $\mathrm{HR}$ were stable, the subjects started to walk on the treadmill at a speed of 2.7 $\mathrm{km} . \mathrm{h}^{-1}$ with a slope of $0 \%$ for three minutes. The speed and slope were adjusted every three minutes until the subjects were exhausted (ACSM, 2013).

The exhaustion criteria of the subjects were as follows: 1) the rating of perceived exertion (RPE) is greater than 19;2) RER is greater than $1.1 ; 3$ ) the estimated $\mathrm{HR}_{\max }$ is more than $90 \%$. When more than two criteria were simultaneously reached, the researchers determined that was the test termination standard. Various respiratory, cardiovascular, and metabolic parameters, such as tidal volume (Vt), RR, $\mathrm{V}_{\mathrm{E}}, \mathrm{HR}, \mathrm{BP}, \mathrm{VO}_{2}, \mathrm{VCO}_{2}, \mathrm{~V}_{\mathrm{E}} / \mathrm{VO}_{2}$, and $\mathrm{V}_{\mathrm{E}} / \mathrm{VCO}_{2}$, were collected during GXT using an energy metabolic measurement system (Cortex Metamax 3B, Germany).

The study determined that VT was according to the criterion that $\mathrm{V}_{\mathrm{E}} / \mathrm{VO}_{2}$ increased gradually accompanied by exercise intensity, but $\mathrm{V}_{\mathrm{E}} / \mathrm{VCO}_{2}$ did not increase simultaneously. $\mathrm{V}_{\mathrm{E}}$ gradually deviated from the linear curve (Beaver et al., 1986). The determination of VT was according to the time chart drawn by the computer, and then VT was independently confirmed by two experienced exercise physiologists. If the determination results were inconsistent, then exercise physiologists were re-evaluated to reach a consensus. For the aerobic endurance test, subjects performed under $80 \%$ VT an intensity treadmill exercise for six minutes. For the aerobic endurance test, subjects performed a treadmill exercise for six minutes under $\Delta 50$ intensity ( $50 \%$ of VT and maximum workload).

HRV was measured with a personal heart rate monitor (Medeia, Bulgaria). All subjects were placed on the ECG patch and rested for ten minutes in a sitting position. Then researchers started to collect HRV data for five minutes. HRV parameters included respiration-frequency area ( $\mathrm{RFa}$, index of parasympathetic activity), low-frequency area (LFa, index of sympathetic activity), and $\mathrm{LFa} / \mathrm{RFa}$ ratio (index of sympathovagal balance).

All respiratory, cardiovascular, and metabolic data collected during the various exercise tests were calculated at an average of 10 seconds. If there was an obvious deviation in the data, such as extreme values due to the subject sneezing or coughing, then that data was deleted. If the average exceeded four standard deviations, then the values were listed as extreme values and deleted. The data were analysed using SPSS for Windows 23.0. One-way ANOVA was used to analyse the anthropometric parameters (age, height, weight, body mass index, systolic blood pressure (SBP), diastolic blood pressure (DBP), and HR) of all groups. The differences of HRV (RFa, $\mathrm{Lfa}$, and $\mathrm{LFa} / \mathrm{RFa})$, respiratory $\left(\mathrm{V}_{\mathrm{E}}, \mathrm{V}_{\mathrm{t}}\right.$, and $\left.\mathrm{RR}\right)$, cardiorespiratory $(\mathrm{HR}, \mathrm{SBP}$, and $\mathrm{DBP})$, and metabolic $\left(\mathrm{VO}_{2}, \mathrm{VCO}_{2}, \mathrm{~V}_{\mathrm{E}} / \mathrm{VO}_{2}\right.$, and $\mathrm{V}_{\mathrm{E}} / \mathrm{VCO}^{2}$ ) parameters in various exercise tests before and after interventions for different groups (timing * groups) were analysed using repeated-measure ANOVA. The Scheffé meth- 
od was used to determine the main effect was significant. Pearson correlation was used to analyse the relationship between HRV and respiratory parameters. The significant level of statistical testing was determined to be $\alpha=.05$.

\section{Results}

A total of 46 subjects in this study completed all the experiments. The anthropometric data of the three groups of subjects show no significant difference (Table 1 ).

Table 1. Basic anthropometrical parameters of the three groups

\begin{tabular}{cccccc}
\hline Parameters & MPU $(\mathrm{n}=16)$ & $\mathrm{MPI}(\mathrm{n}=14)$ & $\mathrm{C}(\mathrm{n}=16)$ & F-value & P-value \\
\hline Age $(\mathrm{yr})$ & $23.2 \pm 2.1$ & $21.8 \pm 2.0$ & $22.8 \pm 1.8$ & 1.94 & 0.16 \\
Height $(\mathrm{cm})$ & $172.8 \pm 6.3$ & $175.1 \pm 8.4$ & $173.0 \pm 5.4$ & 1.94 & 0.16 \\
Weight $(\mathrm{kg})$ & $67.6 \pm 10.6$ & $67.2 \pm 9.2$ & $66.7 \pm 8.0$ & 0.05 & 0.96 \\
BMI $\left(\mathrm{kg} / \mathrm{m}^{2}\right)$ & $23.3 \pm 4.0$ & $22.0 \pm 2.9$ & $22.3 \pm 2.4$ & 0.73 & 0.49 \\
SBP $(\mathrm{mm} \mathrm{Hg})$ & $120.3 \pm 14.8$ & $118.0 \pm 6.2$ & $117.9 \pm 13.2$ & 0.20 & 0.82 \\
DBP $(\mathrm{mm} \mathrm{Hg})$ & $73.8 \pm 11.0$ & $72.5 \pm 10.7$ & $70.5 \pm 9.8$ & 0.38 & 0.68 \\
HR (beat $/ \mathrm{m}-1)$ & $66.0 \pm 10.2$ & $63.6 \pm 13.4$ & $70.3 \pm 14.8$ & 0.97 & 0.39 \\
\hline
\end{tabular}

Note. Data present as mean \pm SD. ${ }^{*} \mathrm{p}<.05$ calculated by one-way ANOVA to compare three groups. MPU: Mentha piperita essential oil uptake group; PI: Mentha piperita essential oil inhalation group; C: control group. BMI: body mass index. SBP: systolic blood pressure. DBP: diastolic blood pressure. HR: heart rate.

Under HRV measurement, there were no significant differences between the three groups before treatments. After MPU intervention, $\mathrm{LFa}\left(1.8 \pm 0.1\right.$ vs $\left.2.2 \pm 0.2 \mathrm{~ms}^{2}, \mathrm{p}=.03\right)$ and
$\mathrm{LFa} / \mathrm{RFa}$ ratio $(0.9 \pm 0.1$ vs $1.3 \pm 0.1, \mathrm{p}=.01)$ increased compared to pre-intervention. There was no significant difference in the MPI and $\mathrm{C}$ groups (Table 2).

Table 2. HRV parameter changes after three interventions

\begin{tabular}{|c|c|c|c|c|c|c|}
\hline \multirow{2}{*}{$\begin{array}{c}\text { Group } \\
\text { Parameters }\end{array}$} & \multicolumn{2}{|c|}{$\operatorname{MPU}(n=16)$} & \multicolumn{2}{|c|}{ MPI $(n=14)$} & \multicolumn{2}{|c|}{$C(n=16)$} \\
\hline & Pre & Post & Pre & Post & Pre & Post \\
\hline $\mathrm{RFa}, \mathrm{ms}^{2}$ & $2.3 \pm 0.2$ & $2.0 \pm 0.3$ & $2.2 \pm 0.2$ & $2.0 \pm 0.2$ & $2.2 \pm 0.2$ & $1.8 \pm 0.3$ \\
\hline $\mathrm{LFa}, \mathrm{ms}^{2}$ & $1.8 \pm 0.1$ & $2.2 \pm 0.2^{*}$ & $1.9 \pm 0.2$ & $2.0 \pm 0.2$ & $1.8 \pm 0.1$ & $1.7 \pm 0.1$ \\
\hline LFa/RFa & $0.9 \pm 0.1$ & $1.3 \pm 0.1^{*}$ & $0.9 \pm 0.1$ & $1.1 \pm 0.1$ & $0.9 \pm 0.1$ & $1.1 \pm 0.1$ \\
\hline
\end{tabular}

Note. Data present as mean \pm SD. ${ }^{*} p<.05$ calculated by repeated-measure ANOVA to compare three groups and pre and post interventions. MPU: Mentha piperita essential oil uptake group; MPI: Mentha piperita essential oil inhalation group; C: control group. Pre: pre-intervention; Post: post-intervention. RFa: respiration frequency area (parasympathetic activity). LFa: low-frequency area (sympathetic activity). LFa/RFa: sympathovagal balance.

For the aerobic exercise test, there was no significant difference in $\mathrm{VO}_{2}, \mathrm{VCO}_{2}, \mathrm{~V}_{\mathrm{E}}, \mathrm{Vt}$, and $\mathrm{RR}$ of the three groups before or after the interventions. For the anaerobic exercise test, there was no significant difference in $\mathrm{VO}_{2}, \mathrm{VCO}_{2}, \mathrm{~V}_{\mathrm{E}}, \mathrm{Vt}$, and
$\mathrm{RR}$ in the MPI and $\mathrm{C}$ groups. However, $\mathrm{VCO}_{2}(41.2 \pm 4.0$ vs $\left.49.2 \pm 6.8 \mathrm{~mL} / \mathrm{min}^{-1} / \mathrm{kg}^{-1}, \mathrm{p}=.03\right), \mathrm{V}_{\mathrm{E}}(80.2 \pm 4.3$ vs $97.5 \pm 5.5 \mathrm{~L} /$ $\left.\mathrm{min}^{-1}, \mathrm{p}=.01\right)$, and RR $\left(38.2 \pm 1.9\right.$ vs $44.3 \pm 2.1$ breath $/ \mathrm{min}^{-1}, \mathrm{p}=$ .04 ) increased significantly after MPU intervention (Table 3).

Table 3. Respiratory and metabolic parameters at aerobic and anaerobic endurance tests after three interventions

\begin{tabular}{|c|c|c|c|c|c|c|}
\hline \multirow{2}{*}{$\begin{array}{c}\text { Groups } \\
\text { Parameters }\end{array}$} & \multicolumn{2}{|c|}{ MPU $(n=16)$} & \multicolumn{2}{|c|}{ MPI $(n=14)$} & \multicolumn{2}{|c|}{$C(n=16)$} \\
\hline & Pre & Post & Pre & Post & Pre & Post \\
\hline \multicolumn{7}{|c|}{ Aerobic endurance test } \\
\hline $\mathrm{VO}_{2}\left(\mathrm{~mL} / \mathrm{min}^{-1} / \mathrm{kg}^{-1}\right)$ & $26.2 \pm 9.0$ & $25.0 \pm 6.8$ & $28.1 \pm 5.1$ & $29.7 \pm 2.8$ & $28.7 \pm 5.3$ & $29.7 \pm 3.7$ \\
\hline $\mathrm{VCO}_{2}\left(\mathrm{~mL} / \mathrm{min}^{-1} / \mathrm{kg}^{-1}\right)$ & $24.1 \pm 7.7$ & $23.5 \pm 5.0$ & $26.6 \pm 5.6$ & $25.0 \pm 5.2$ & $24.0 \pm 3.1$ & $25.9 \pm 2.9$ \\
\hline $\mathrm{V}_{\mathrm{E}}\left(\mathrm{L} / \mathrm{min}^{-1}\right)$ & $60.2 \pm 9.3$ & $59.2 \pm 7.5$ & $60.2 \pm 9.1$ & $63.8 \pm 8.0$ & $60.6 \pm 7.8$ & $59.8 \pm 6.5$ \\
\hline $\mathrm{Vt}\left(\mathrm{L} / \mathrm{min}^{-1}\right)$ & $1.8 \pm 0.6$ & $1.7 \pm 0.4$ & $1.9 \pm 0.5$ & $1.9 \pm 0.3$ & $1.8 \pm 0.4$ & $1.8 \pm 0.5$ \\
\hline RR (breath/min ${ }^{-1}$ ) & $33.4 \pm 3.4$ & $34.1 \pm 2.9$ & $31.7 \pm 3.0$ & $33.6 \pm 2.5$ & $33.7 \pm 1.8$ & $33.2 \pm 2.7$ \\
\hline \multicolumn{7}{|c|}{ Anaerobic endurance test } \\
\hline $\mathrm{VO}_{2}\left(\mathrm{~mL} / \mathrm{min}^{-1} / \mathrm{kg}^{-1}\right)$ & $37.0 \pm 3.1$ & $35.3 \pm 4.4$ & $32.4 \pm 7.0$ & $33.3 \pm 4.4$ & $35.2 \pm 6.4$ & $34.9 \pm 3.2$ \\
\hline $\mathrm{VCO}_{2}\left(\mathrm{~mL} / \mathrm{min}^{-1} / \mathrm{kg}^{-1}\right)$ & $41.2 \pm 4.0$ & $49.2 \pm 6.8^{*}$ & $40.4 \pm 3.9$ & $41.8 \pm 2.7$ & $42.3 \pm 4.4$ & $40.4 \pm 4.2$ \\
\hline $\mathrm{V}_{\mathrm{E}}\left(\mathrm{L} / \mathrm{min}^{-1}\right)$ & $80.2 \pm 4.3$ & $97.5 \pm 5.5^{*}$ & $83.5 \pm 5.8$ & $82.3 \pm 4.6$ & $84.4 \pm 10.1$ & $81.5 \pm 9.7$ \\
\hline $\mathrm{Vt}\left(\mathrm{L} / \mathrm{min}^{-1}\right)$ & $2.1 \pm 1.0$ & $2.2 \pm 1.3$ & $2.0 \pm 0.9$ & $2.1 \pm 1.5$ & $2.1 \pm 1.3$ & $2.0 \pm 0.9$ \\
\hline RR (breath/min ${ }^{-1}$ ) & $38.2 \pm 1.9$ & $44.3 \pm 2.1^{*}$ & $41.8 \pm 2.6$ & $39.2 \pm 3.2$ & $40.2 \pm 1.8$ & $40.8 \pm 2.0$ \\
\hline
\end{tabular}

Note. Data present as mean \pm SD. ${ }^{*} \mathrm{p}<.05$ calculated by repeated-measure ANOVA to compare three groups and pre and post interventions. MPU: Mentha piperita essential oil uptake group; $\mathrm{MPI}$ : Mentha piperita essential oil inhalation group; C: control group. Pre: pre-intervention; Post: post-intervention. VO ${ }_{2}$ : oxygen consumption; $\mathrm{VCO}_{2}$ : carbon dioxide production; $\mathrm{V}_{\mathrm{E}}$ : ventilation per minute; $\mathrm{Vt}$ : tidal volume; RR: respiratory rate; $\mathrm{HR}$ : heart rate.

Before the intervention, the respiratory, cardiovascular, and metabolic parameters had no significant differences at VT or maximal exercise during GXT among the three groups. After 10 days of intervention, while there was no significant differ- 
ence in exercise time, $\mathrm{VO}_{2}, \mathrm{VCO}_{2}, \mathrm{~V}_{\mathrm{E}}, \mathrm{Vt}, \mathrm{RR}, \mathrm{V}_{\mathrm{E}} / \mathrm{VO}_{2}$, and $\mathrm{V}_{\mathrm{E}} /$ $\mathrm{VCO}_{2}$ following MPI and $\mathrm{C}$ interventions. However, $\mathrm{VCO}_{2 \max }$ $\left(51.9 \pm 3.5\right.$ vs $\left.59.1 \pm 6.4 \mathrm{~mL} / \mathrm{min}^{-1} / \mathrm{kg}^{-1}, \mathrm{p}=.01\right), \mathrm{V}_{\text {Emax }}(126.4 \pm 6.5$ vs $\left.138.4 \pm 5.4 \mathrm{~L} / \mathrm{min}^{-1}, \mathrm{p}=.01\right), \mathrm{RR}_{\max }(52.7 \pm 3.6 \mathrm{vs}, 60.1 \pm 2.3$ breath $\left./ \mathrm{min}^{-1}, \mathrm{p}=.01\right)$, and $\mathrm{V}_{\mathrm{E}} / \mathrm{VCO}_{2}(33.1 \pm 4.0$ vs $38.9 \pm 4.9, \mathrm{p}=$ $.01)$ significantly increased in the MPU group (Table 4 ).

Table 4. Respiratory, cardiovascular and metabolic parameters during GXT after three interventions

\begin{tabular}{|c|c|c|c|c|c|c|}
\hline \multirow{2}{*}{$\begin{array}{c}\text { Groups } \\
\text { Parameters }\end{array}$} & \multicolumn{2}{|c|}{ MPU $(n=16)$} & \multicolumn{2}{|c|}{ MPI $(n=14)$} & \multicolumn{2}{|c|}{$C(n=16)$} \\
\hline & Pre & Post & Pre & Post & Pre & Post \\
\hline \multicolumn{7}{|c|}{ Ventilatory threshold } \\
\hline Exercise time (s) & $581.0 \pm 90.8$ & $557.0 \pm 100.4$ & $612.3 \pm 114.3$ & $583.1 \pm 103.2$ & $565.1 \pm 84.8$ & $559.5 \pm 110.0$ \\
\hline $\mathrm{VO}_{2}\left(\mathrm{~mL} / \mathrm{min}^{-1} / \mathrm{kg}^{-1}\right)$ & $37.5 \pm 5.7$ & $37.3 \pm 7.6$ & $35.4 \pm 5.9$ & $33.4 \pm 9.7$ & $36.8 \pm 5.6$ & $37.9 \pm 6.5$ \\
\hline $\mathrm{VCO}_{2}\left(\mathrm{~mL} / \mathrm{min}^{-1} / \mathrm{kg}^{-1}\right)$ & $36.8 \pm 6.7$ & $37.6 \pm 7.2$ & $34.0 \pm 6.2$ & $32.2 \pm 8.9$ & $36.4 \pm 5.5$ & $37.2 \pm 6.4$ \\
\hline $\mathrm{V}_{\mathrm{E}}\left(\mathrm{L} / \mathrm{min}^{-1}\right)$ & $70.2 \pm 13.5$ & $69.7 \pm 14.5$ & $67.2 \pm 9.9$ & $68.3 \pm 7.8$ & $65.5 \pm 10.8$ & $63.9 \pm 15.1$ \\
\hline $\mathrm{Vt}\left(\mathrm{L} / \mathrm{min}^{-1}\right)$ & $1.9 \pm 0.4$ & $1.9 \pm 0.4$ & $1.7 \pm 0.4$ & $1.7 \pm 0.3$ & $1.8 \pm 0.4$ & $2.0 \pm 0.6$ \\
\hline RR (breath/min ${ }^{-1}$ ) & $37.4 \pm 8.1$ & $36.6 \pm 8.3$ & $41.4 \pm 7.7$ & $42.9 \pm 10.0$ & $36.9 \pm 8.3$ & $33.3 \pm 7.5$ \\
\hline $\mathrm{V}_{\mathrm{E}} / \mathrm{NO}_{2}$ & $25.6 \pm 3.4$ & $25.1 \pm 4.1$ & $27.3 \pm 2.7$ & $27.4 \pm 4.2$ & $26.9 \pm 5.9$ & $24.7 \pm 2.4$ \\
\hline $\mathrm{V}_{\mathrm{E}} / \mathrm{VCO}_{2}$ & $27.7 \pm 2.9$ & $29.8 \pm 3.1$ & $30.4 \pm 4.0$ & $30.7 \pm 3.8$ & $30.4 \pm 6.2$ & $29.9 \pm 2.7$ \\
\hline \multicolumn{7}{|c|}{ Maximal exercise } \\
\hline Exercise time (s) & $847.4 \pm 127.3$ & $861.1 \pm 89.0$ & $907.7 \pm 156.4$ & $891.3 \pm 156.5$ & $828.0 \pm 74.0$ & $821.7 \pm 81.8$ \\
\hline HR (breath/min ${ }^{-1}$ ) & $187.3 \pm 6.0$ & $189.8 \pm 5.6$ & $189.9 \pm 9.8$ & $188.8 \pm 8.9$ & $191.4 \pm 11.7$ & $193.6 \pm 10.1$ \\
\hline $\mathrm{VO}_{2}\left(\mathrm{~mL} / \mathrm{min}^{-1} / \mathrm{kg}^{-1}\right)$ & $52.0 \pm 5.9$ & $55.5 \pm 6.0$ & $50.8 \pm 6.8$ & $52.5 \pm 8.6$ & $51.0 \pm 7.1$ & $53.9 \pm 7.6$ \\
\hline $\mathrm{VCO}_{2}\left(\mathrm{~mL} / \mathrm{min}^{-1} / \mathrm{kg}^{-1}\right)$ & $51.9 \pm 3.5$ & $59.1 \pm 6.4^{*}$ & $53.4 \pm 7.5$ & $52.3 \pm 4.7$ & $50.8 \pm 3.0$ & $48.9 \pm 4.1$ \\
\hline $\mathrm{V}_{\mathrm{E}}\left(\mathrm{L} / \mathrm{min}^{-1}\right)$ & $126.4 \pm 6.5$ & $138.4 \pm 5.4^{*}$ & $121.8 \pm 7.3$ & $126.6 \pm 4.4$ & $123.1 \pm 5.1$ & $120.8 \pm 7.9$ \\
\hline $\mathrm{Vt}\left(\mathrm{L} / \mathrm{min}^{-1}\right)$ & $2.4 \pm 0.4$ & $2.3 \pm 0.4$ & $2.2 \pm 0.5$ & $2.3 \pm 0.6$ & $2.4 \pm 0.4$ & $2.4 \pm 0.4$ \\
\hline RR (breath/min ${ }^{-1}$ ) & $52.7 \pm 3.6$ & $60.1 \pm 2.3^{*}$ & $55.4 \pm 4.0$ & $55.0 \pm 2.1$ & $51.3 \pm 6.4$ & $50.3 \pm 5.1$ \\
\hline $\mathrm{V}_{\mathrm{E}} / \mathrm{NO}_{2}$ & $31.6 \pm 4.9$ & $34.2 \pm 5.1$ & $34.8 \pm 5.2$ & $36.6 \pm 5.1$ & $33.1 \pm 4.6$ & $34.8 \pm 3.7$ \\
\hline $\mathrm{V}_{\mathrm{E}} / \mathrm{VCO}_{2}$ & $33.1 \pm 4.0$ & $38.9 \pm 4.9^{*}$ & $33.7 \pm 7.0$ & $36.3 \pm 5.1$ & $33.1 \pm 4.3$ & $32.2 \pm 2.6$ \\
\hline
\end{tabular}

Note. Data present as mean \pm SD. ${ }^{*} p<.05$ calculated by repeated-measure ANOVA to compare three groups and pre and post interventions. MPU:

Mentha piperita essential oil uptake group; MPI: Mentha piperita essential oil inhalation group; C: control group. Pre: pre-intervention; Post: postintervention. $\mathrm{HR}$ : heart rate; $\mathrm{VO}_{2}$ : oxygen consumption; $\mathrm{VCO}_{2}$ : carbon dioxide production; $\mathrm{V}_{\mathrm{E}}$ : ventilation in minutes; $\mathrm{Vt}$ : tidal volume; $\mathrm{RR}$ : respiratory rate.

Correlation analysis was used to explore the HRV and respiratory parameters following MPU. After analysis the difference values of $\mathrm{LFa}$ at baseline and $\mathrm{RR}, \mathrm{V}_{\mathrm{E}}, \mathrm{VCO}_{2}$, and $\mathrm{Vt}$ at maximal exercise before and after MPU intervention, the correlations of $\Delta \mathrm{LFa}$ with $\Delta \mathrm{RR}_{\max }(\mathrm{r}=.90, \mathrm{p}=.01), \Delta \mathrm{V}_{\mathrm{Emax}}(\mathrm{r}=.85, \mathrm{p}=.01)$, and $\Delta \mathrm{VCO}_{2 \max }(\mathrm{r}=.80, \mathrm{p}=.01)$ were significant (Figure 2$)$.
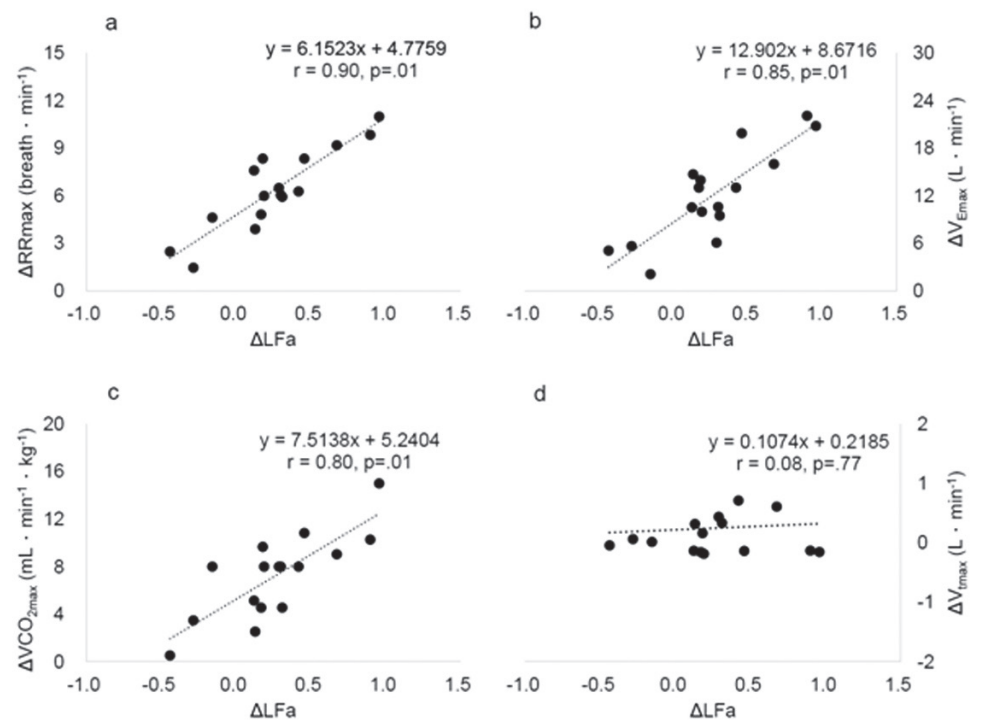

Figure 1. Correlation analysis of pulmonary parameters and HRV by Pearson correlation in MPU. MPU: Mentha piperita essential oil uptake group. $\triangle \mathrm{RRmax}$ : difference values of respiratory rate between baseline and maximal exercise. $\Delta \mathrm{V}_{\text {Emax }}$ : difference values of ventilation in minute between baseline and maximal exercise. $\Delta \mathrm{CO}_{2 \max }$ : difference values of carbon dioxide production between baseline and maximal exercise. $\Delta \mathrm{V}_{\text {tmax }}$ : difference values of tidal volume between baseline and maximal exercise. $\Delta \mathrm{LFa}$ : difference values of low-frequency area (sympathetic activity) between pre-intervention and post-intervention. 


\section{Discussion}

To the authors' best knowledge, this is the first study to design RCT experiments with a relatively large sample size to investigate the effects of MP essential oil uptake or inhalation for 10 consecutive days on HRV on resting and respiratory, cardiovascular, and metabolic regulation during various exercise intensities. The main findings of this study are 1) both the uptake and the inhalation of 50uL of MP essential oil for 10 consecutive days does not increase aerobic capacity and maximal exercise performance; 2) the 10 days' uptake of MP essential oil enhances the sympathetic activity and sympathovagal balance at rest, but the inhalation of MP essential oil does not have this effect; 3 ) the 10 days' uptake of MP essential oil increases $\mathrm{RR}, \mathrm{V}_{\mathrm{E}}$, and $\mathrm{VCO}_{2}$ at higher intensity exercise (higher than VT), which may relate to sympathetic activation.

The results of this study are similar to those of Shepherd and Peart, who found that the uptake of 50uL of MP essential oil for 10 consecutive days did not improve maximal performance or aerobic capacity (Shepherd \& Peart, 2017). However, Meamarbashi and Rajabi (2013) recruited 12 healthy male subjects for the uptake of $50 \mathrm{uL}$ of MP essential oil for 10 consecutive days and found that the maximum oxygen uptake increased by $10.5 \%$, exhaustion exercise time increased by $24.9 \%$, and work volume increased by $51.5 \%$. Although the results of Meamarbashi and Rajabi (2013) determined that the uptake of MP essential oil was helpful for aerobic capacity and athletic performance, the experimental design lacked a control group, and thus the supplementary benefit may be the learning effect of the subjects after two exercise tests. To be cautious, this study designed an aerobic endurance test $(80 \% \mathrm{VT})$ and showed no significant change in $\mathrm{VO}_{2}, \mathrm{VCO}_{2}, \mathrm{~V}, \mathrm{Vt}$, and $\mathrm{RR}$ regardless of uptake or inhalation of MP essential oil. Therefore, we confirm that uptake or inhalation of 50uL MP essential oil for 10 days has no significant effect on aerobic capacity.

Previous studies have confirmed that the uptake of MP essential oil has beneficial effects on lung functions. Meamarbashi and Rajabi (2013) noted that lung function (such as FVC, PEF, and PIF) increased significantly after 10 days of supplementation of MP essential oil. Meamarbashi (2014) used the supplementation of MP essential oil once and found that $\mathrm{FVC}_{1}, \mathrm{PEF}$, and PIF all increased significantly after 5 minutes of supplementation. A more recent study by Shepherd and Peart (2017) pointed out that there was no obvious change in $\mathrm{FVC}, \mathrm{FVC}_{1}$, and $\mathrm{FVC}_{1} / \mathrm{FVC}$ under the supplementation of peppermint oil for 10 consecutive days, and there was only an increase in chest circumference at the maximum exhale. Although the lung function was not measured in this study, $\mathrm{V}_{\mathrm{E}}$ and RR during anaerobic exercise and GXT significantly increased following MPU intervention. This might be the benefit of improved lung part of function after MP essential oil uptake, but even if respiratory-regulated functions were improved in a short period, there were not sufficient to enhance aerobic, anaerobic, and maximal exercise performance.

The notable findings of this study are that $\mathrm{LFa}, \mathrm{LFa} / \mathrm{RFa}, \mathrm{V}_{\mathrm{E}}$, $\mathrm{RR}$, and $\mathrm{VCO}_{2}$ increased after 10 days' MP essential oil uptake. The changes of $\mathrm{V}_{\mathrm{E}}, \mathrm{RR}$, and $\mathrm{VCO}_{2}$ are related to sympathetic activity activation. Sönmez (2010) randomly divided subjects into a mint group, placebo group, and control group. The mint group was supplemented with a water solution soaked in mint leaves and did not affect 400-metre running speed. However, the concentration of lactic acid in the blood was significantly lower than that of the placebo group and the control group.
Sönmez (2010) indicated that mint oil may be related to accelerating lactic acid clearance, but the detailed mechanism for affecting lactic acid clearance was not explained. Another research result of Meamarbashi and Rajabi (2013) showed that $\mathrm{VCO}_{2}, \mathrm{~V}_{\mathrm{E}}, \mathrm{RR}$, and Vt increased significantly, while $\mathrm{P}_{\mathrm{ET}} \mathrm{CO}_{2}$ decreased significantly. The increase in $\mathrm{VCO}_{2}$ was similar to our study, in which the increase in $\mathrm{V}_{\mathrm{E}}, \mathrm{RR}$, and $\mathrm{VCO}_{2}$ occurred under anaerobic and GXT. This may mean that respiratory regulation changed by MP essential oil uptake may participate in the removal of anaerobic metabolites.

Nair (2001) indicated that isolated clinical cases of peppermint oil and/or its constituents had been reported; peppermint oil (8\%) was not a sensitizer when tested using a maximization protocol; however, the concentration of Pulegone in peppermint oil should not exceed $1 \%$ to ensure safety. Meamarbashi and Rajabi (2013) recruited 30 healthy male college students as subjects and randomly assigned them to the experimental and control groups. The experimental group was orally supplemented with 50ul of peppermint essential oil (100\%). Meamarbashi (2014) designed 12 healthy male students who supplemented $500 \mathrm{~mL}$ aqueous solution with $0.05 \mathrm{~mL}$ peppermint essential oil $(0.01 \%)$ for ten consecutive days. Shepherd and Peart (2017) recruited seven healthy subjects who supplemented with $0.05 \mathrm{ml}$ in $500 \mathrm{ml}$ mint water solution $(0.01 \%)$ for 10 days. A relatively recent study indicated that 19 subjects were treated with repeated menthol mouth swilling $(0.1 \%$ concentration). Repeated menthol mouth swilling does not improve strength or power performance. (Best et al., 2020). In this study, the MPU group was supplemented with $50 \mathrm{uL} \mathrm{MP}$ essential oil dissolved in a $500 \mathrm{~mL}$ aqueous solution $(0.01 \%)$. In the MPI group, 50uL MP essential oil was dissolved in $50 \mathrm{ml}$ of aqueous solution $(0.1 \%)$ and inhaled odour, which was produced by an ultrasonic spray manufacturing machine. Therefore, the concentration of MP essential oil in this study was between $0.01-0.1 \%$, which is similar to the MP essential oil dosage of previous studies (Best et al., 2020; Meamarbashi, 2014; Meamarbashi \& Rajabi, 2013; Shepherd \& Peart, 2017).

This study confirmed that 50ul MP essential oil intake for 10 consecutive days increased sympathetic nerve activity in resting and which relative to increase $\mathrm{RR}, \mathrm{V}_{\mathrm{E}}$, and $\mathrm{VCO}_{2}$ during high-intensity exercise. It is speculated that the possible mechanisms are that the menthol of MP essential oil stimulated sympathetic nerve activity to 1 ) increase bronchiectasis (Zänker et al. 1980), thus affecting FVC, PEP, and PIF (Jaradat et al. 2016; Meamarbashi 2014; Meamarbashi and Rajabi 2013); 2) promote stimulation of adrenaline secretion (Haze et al. 2002), increase liver glucose release, and changed the energy metabolism. Acidic substances after carbohydrate metabolism would stimulate respiratory regulation and assist in the elimination of lactic acid (Sönmez et al., 2010). Although this study did not analyse blood biochemical parameters from the subjects, it observed that timings of VT at GXT were earlier following uptake or inhalation of MP essential oil. These all indirectly indicate the possible effects of MP essential oil on respiratory and metabolic regulation during exercise.

Although all variables that may affect the experimental results were controlled as much as possible, there were still many research restrictions beyond our control. 1) Because MP essential oil has a strong fragrance, it is difficult to design a placebo with a similar fragrance but a different composition; thus, it is difficult to adopt the double-blind experimental design. 2) This study only discussed the effects of the uptake or 
inhalation of MP essential oil on HRV, respiratory cardiovascular, and metabolic regulation at various exercise intensities but did not analysis the blood biochemical values of subjects. In this study, we attempted to find possible mechanisms by using non-invasive methods. Therefore, many complex phenomena cannot be further explained. We suggested that future studies explore the possible effects of MP essential oil on integrative physiological regulation by blood biochemical values.

To our knowledge, this is the first study that compared the effect of uptake or inhalation of MP essential oil on HRV at resting, respiratory, cardiovascular, and metabolic regulation at various exercise intensities. This study confirmed that the uptake or inhalation of 50uL of MP essential oil for 10 consecutive days does not improve the aerobic capacity and maximal exercise performance of healthy young males. However, the uptake of MP essential oil for 10 consecutive days does enhance sympathetic activity and the sympathovagal balance. The activation of sympathetic nerve activity is related to the enhanced respiratory regulation during high-intensity exercise.

\section{Acknowledgements}

We thank the volunteers for their participation. This study was supported by the National Science Council of Taiwan (NSC 104-2410-H-562-001).

\section{References}

Ahijevych, K., \& Garrett, B. E. (2004). Menthol pharmacology and its potential impact on cigarette smoking behavior. Nicotine \& Tobacco Research, 6(Suppl1), S17-28. doi: 10.1080/14622200310001649469

Alammar, N., Wang, L., Saberi, B., Nanavati, J., Holtmann, G., Shinohara, R. T., \& Mullin, G. E. (2019). The impact of peppermint oil on the irritable bowel syndrome: a metaanalysis of the pooled clinical data. BMC Complementary Medicine and Therapies, 19(1), 21. doi: 10.1186/s12906018-2409-0

Asghar, S. (2011). Effects of Mentha piperita inhalation on VO2max and reaction time, on man elite karate-do. Annals of Biological Research, 2(6), 84-87.

Barker, S., Grayhem, P., Koon, J., Perkins, J., Whalen, A., \& Raudenbush, B. (2003). Improved performance on clerical tasks associated with administration of peppermint odor. Perceptual and Motor Skills, 97(3 Pt 1), 1007-1010. doi: 10.2466/pms.2003.97.3.1007

Beaver, W. L., Wasserman, K., \& Whipp, B. J. (1986). A new method for detecting anaerobic threshold by gas exchange. Journal of Applied Physiology, 60(6), 2020-2027. doi: 10.1152/jappl.1986.60.6.2020

Best, R., Temm, D., Hucker, H., \& McDonald, K. (2020). Repeated Menthol Mouth Swilling Affects Neither Strength nor Power Performance. Sports (Basel), 8(6). doi: $10.3390 /$ sports 8060090

Chang, K. M., \& Shen, C. W. (2011). Aromatherapy benefits autonomic nervous system regulation for elementary school faculty in taiwan. Evidence-Based Complementary and Alternative, 2011, 946537. doi: 10.1155/2011/946537

Elshafie, H. S., \& Camele, I. (2017). An Overview of the Biological Effects of Some Mediterranean Essential Oils on Human Health. BioMed Research International, 2017, 9268468. doi: $10.1155 / 2017 / 9268468$

Gobel, H., Schmidt, G., \& Soyka, D. (1994). Effect of peppermint and eucalyptus oil preparations on neurophysiological and experimental algesimetric headache parameters. Cephalalgia, 14(3), 228-234; discussion 182. doi: 10.1046/j.1468-2982.1994.014003228.x

Haze, S., Sakai, K., \& Gozu, Y. (2002). Effects of fragrance inhalation on sympathetic activity in normal adults. Japanese Journal of Pharmacology, 90(3), 247-253. doi: 10.1254/jjp.90.247

Horii, Y., Maeda, K., Shen, J., Fujisaki, Y., \& Nagai, K. (2015). Effect of grapefruit and lavender essential oil scents on pancreatic sympathetic nerve activity and plasma glucose in rats. Flavour and Fragrance Journal, 30(4), 282-287. doi: 10.1002/ff. 3243

Jaradat, N. A., Al Zabadi, H., Rahhal, B., Hussein, A. M., Mahmoud, J. S., Mansour, B., . . . Issa, A. (2016). The effect of inhalation of Citrus sinensis flowers and Mentha spicata leave essential oils on lung function and exercise performance: a quasi-experimental uncontrolled beforeand-after study. Journal of the International Society of Sports Nutrition, 13, 36. doi: 10.1186/s12970-016-0146-7

Mauskop, A. (2001). Alternative therapies in headache. Is there a role? Medical Clinics of North America, 85(4), 1077-1084.

McCaffrey, R., Thomas, D. J., \& Kinzelman, A. O. (2009). The Effects of Lavender and Rosemary Essential Oils on Test-Taking Anxiety among Graduate Nursing Students. Holistic Nursing Practice, 23(2), 88-93. doi: 10.1097/ HNP.0b013e3181a110aa

McKay, D. L., \& Blumberg, J. B. (2006). A review of the bioactivity and potential health benefits of peppermint tea (Mentha piperita L.). Phytotherapy Research, 20(8), 619633. doi: $10.1002 /$ ptr.1936

Meamarbashi, A. (2014). Instant effects of peppermint essential oil on the physiological parameters and exercise performance. Avicenna Journal of Phytomedicine, 4(1), 72-78.

Meamarbashi, A., \& Rajabi, A. (2013). The effects of peppermint on exercise performance. International Society of Sports Nutrition, 10(1), 15. doi: 10.1186/1550-2783-1015

American College of Sport Medicine (2013). ACSM's guidelines for exercise testing and prescription: Lippincott Williams \& Wilkins.

Nair, B. (2001). Final report on the safety assessment of Mentha Piperita (Peppermint) Oil, Mentha Piperita (Peppermint) Leaf Extract, Mentha Piperita (Peppermint) Leaf, and Mentha Piperita (Peppermint) Leaf Water. International Journal of Toxicology, 20 (Suppl 3), 61-73.

Pournemati, P., Azarbayjani, M. A., Rezaee, M. B., Ziaee, V., \& Pournemati, P. (2009). The effect of inhaling peppermint odor and ethanol in women athletes. Bratislavske Lekarske Listy, 110(12), 782-787.

Raudenbush, B., Corley, N., \& Eppich, W. (2001). Enhancing athletic performance through the administration of peppermint odor. Journal of Sport \& Exercise Psychology, 23(2), 156-160. doi: 10.1123/jsep.23.2.156

Raudenbush, B., Meyer, B., \& Eppich, W. (2002). The effects of odors on objective and subjective measures of athletic performance. International Sports Journal, 6.

Rohloff, J. (1999). Monoterpene composition of essential oil from peppermint (Mentha x piperita L.) with regard to leaf position using solid-phase microextraction and gas chromatography/mass spectrometry analysis. Journal of 
Agricultural and Food Chemistry, 47(9), 3782-3786.

Sönmez, G., Çolak, M., Sönmez, S., \& Schoenfeld, B. (2010). Effects of oral supplementation of mint extract on muscle pain and blood lactate. Biomedical Human Kinetics, 2(1).

Scherer, R., Lemos, M. F., Lemos, M. F., Martinelli, G. C., Martins, J. D. L., \& da Silva, A. G. (2013). Antioxidant and antibacterial activities and composition of Brazilian spearmint (Mentha spicata L.). Industrial Crops and Products, 50, 408-413. doi: 10.1016/j.indcrop.2013.07.007

Seo, J. Y. (2009). [The effects of aromatherapy on stress and stress responses in adolescents]. Journal of Korean Academy of Nursing, 39(3), 357-365. doi: 10.4040/jkan.2009.39.3.357
Shepherd, K., \& Peart, D. J. (2017). Aerobic capacity is not improved following 10-day supplementation with peppermint essential oil. Applied Physiology, Nutrition, and Metabolism, 42(5), 558-561. doi: 10.1139/apnm-20160603

Watanabe, E., Kuchta, K., Kimura, M., Rauwald, H. W., Kamei, T., \& Imanishi, J. (2015). Effects of bergamot (Citrus bergamia (Risso) Wright \& Arn.) essential oil aromatherapy on mood states, parasympathetic nervous system activity, and salivary cortisol levels in 41 healthy females. Forschende Komplementärmedizin, 22(1), 43-49. doi: 10.1159/000380989 